\title{
LAS DIFICULTADES DE LA UNIDAD POLITICA EN LA HISPANIA VISIGODA: LAS CONTROVERSIAS ENTRE LA REALEZA Y LA NOBLEZA EN EL SIGLO VII
}

RENAN FRIGHETTO"

\section{RESUMEN}

Los problemas vinculados a la concentración del poder en torno a la figura real pueder comprenderse como el resultado de un proceso de transición desde la Antigūedad Clásica a la Edad Media. Por ciento que ia Antigùedad Tardia (siglos IV-VII) se presenta a si mísma como un periodo de confrontación institucional entre la realeza y la nobleza, lo cual culmínó con el debilitamiento de la primera y el fortalecimiento de la segunda. En este estudio nosotros centramos nuestro análisis sobre el reino Hispano-Visigodo de Toledo (siglos VI-VIII), cuyas fuentes históricas reflejan con gran intensidad las dificultades encontradas por los monarcas hispano-visigodos en sus intentos para unir a Hispania politicamente.

Palabras claves: España visigoda, siglos VI-VIII.

\section{ABSTRACT}

The problems related to the concentration of power around the royal figure can be understood as the resuit of the process of transition from Classic Antiquity to the Middle Ages. Indeed Late Antiquity (centuries IV-VII) presents itself as a period of institutional confrontation between the royalty and the nobility, which culminated with the weakening of the first and the strengthening of the second. In the present study we are centering our analysis on the Hispano-Visigoth kindgom of Toledo (centuries VI-VIII), whose historical sources reflect with great intensity the difficulties met by the Hispano-Visigoth monarchs in their attempts to politically unify Hispania,

Keywords: Hispania visigoda, centuries VI-VIII.

Los estudios dedicados a la Hispania visigoda han recibido tanto de parte de los historiadores como de los arqueólogos y filólogos, un notable impulso y desarrollo en los últimos an̂os. De hecho constatamos que a lo largo de este último medio siglo una considerable cantidad de congresos y encuentros de carácter académico-cientifico han dirigido sus temáticas hacia los más diversos aspectos de la sociedad hispano-visigoda', Además, la abundancia de publicaciones académicas, tanto aquéllas destinadas al análisis histórico más detallado o aquéllas destinadas a la traducción de las fuentes históricas hispano-visigodas, sirven para revelarnos la importancia consagrada por parte de la investigación histórica de esta sociedad hispano-visigoda presentada como la sociedad del Occidente tardo antiguo que mejor preservó toda la tradición histórico-cultural de la época bajo imperial romana. En efecto, varios estudios realizados por investigadores de gran talla

\footnotetext{
- Doctor en Historia Antigua por la Universidad de Salamuaca; Profescor Tituiar III de Historia Antiguit - UFPR; trabajo vinculado al proyecto de investagacion "O poder tégio e a sua legitimidade no reuno hispano-visigodo de Toledo (Ss. VI.VHY" - CNPq 2003-1. UFPR) CNPq - Brasil.

1. De los varios congresos realizados destacamos Ganzalez. Blanco, A. (Org.). 1986, Antigiandad y Cristianismo MI. Los Visigados. Histonia y Chi.

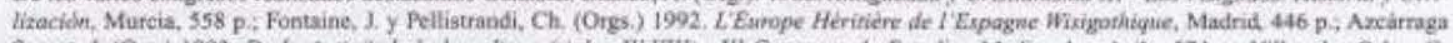
Servet, J. (Org.) 1993. De fa Anilgiedod al medievo (siglos W-VIII) - Ill Congreso de Estudins Medievales, Avila, 574 p.; Villapalos Salas, G. (Org.) 1998. Las Visigodos y su numdo - Arqueologia. Paleontologia y Emargnafia, Madrid 467 p.
} 
cientifica, como Claudio Sánchez Albornoz ${ }^{2}$, M.C. Diaz y Diaz', J, Orlandis', J. Fontaíne', C. Codoñer Merino ${ }^{6}$, L, A, Garcia Moreno' y Pablo Diaz Martinez', entre muchos otros, han destacado en qué medida la tradición bajo imperial romana quedó preservada en la sociedad hispano-visigoda.

Esta idea de manutención y supervivencia de los elementos institucionales, politicos y culturales del mundo bajo imperial romano y su integración a los elementos preexistentes tanto en el mundo de las provincias como también entre los "nuevos" aliados germánicos, nos lleva a pensar en un proceso de continuidad histórica de larga duración, lo cual entendemos como caracteristico de esta transición entre la Antigüedad Clásica y la Edad Media, conocida también como Antigüedad Tardia'. Por lo tanto debemos decir que según la provincia, quizás incluso la región, podemos tener una velocidad de integración o cambios que pueden presentarnos la Antigüedad Tardia, en términos cronológicos, hasta comienzos del siglo VII, o hasta la llegada de los soberanos carolingios en la segunda mitad del siglo VIII, o mismo hasta la configuración y solidificación del reino cristiano de las Asturias en la primera mitad del siglo IX ${ }^{\circ}$. Ante todo hay que buscar definir qué aspectos o temas intentaremos analizar para verificar la posibilidad de utilización de este concepto. Según nuestra interpretación, desde el punto de vista político y de la construcción ideológíca de la superioridad del princeps christianus sacratissimus con respecto a sus pares nobiliarios, si podemos constatar elementos caracteristicos de la Antigüedad Tardía en la Hispania visigoda, aunque tengamos que decir que tratamos de elementos de cariz teórico ya que en la práctica notamos un proceso contrario al fortalecimiento del soberano, una tendencia hacia la regionalización y la protofeudalización" ${ }^{\prime \prime}$. Esta aparente contradicción, pervivencia de elementos teóricos unificadores y universales al lado de actitudes de confrontación, fragmentación y ruptura en contra de aquel que intentaba mantener el poder, puede ser un sintoma de este tiem. po de transición, indudablemente uno de los periodos más interesantes de la historia del mundo mediterráneo.

El estudio de las concepciones ideológicas y teóricas sobre el poder regio en la Antigüedad Tardía occidental ganó un gran incremento en el últímo decenio del siglo XX. De hecho, el análisis detenido de esta cuestión en las fuentes tardo-antiguas nos lleva hacia una interesante confrontación de los segmentos más importantes del universo sociopolitico de las monarquias romano-germánicas occidentales. Un choque que acabó por generar inestabilidades politicas internas y que llevaron a la consecución de acciones tiránicas y usurpatorias en contra del poder del monarca legitimo que, al fin y al cabo, de acuerdo con Diaz Martínez, sirvieron como elementos esenciales en el futuro equilibrio institucional de aquellas monarquias ${ }^{12}$. Esta confrontación por el control efectivo del poder politico entre el rey y la nobleza de primera línea, denominada

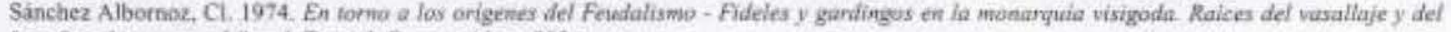
beneficio hispanos. - Libro L, Tomo L, Buenos Aires, 203 p.

De los trabajos hechos por Diaz y Diaz se deben destacar Diaz y Diaz, M.C. 1958. Anedocta Wisigothica f. Ertudias y edicionex de texios litera. mos menones de equoca visigoda, Salamanca, 134 p.; Diaz y Diaz, M.C. "Introduceión general", in: Oroz Reta, L y Marcos Casquero, M.A. 19 B2. Sian Lidiaro de Sewilia - Enimologias I. Madrid pp.7-257.

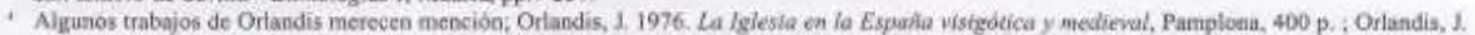
y Ramos Lissón. D. 1986. Historia de los Concilias de la Espaila romana y visigada. Pamplona, 530 p. ; Otlandis, 1. 1987. Historia de Espania -

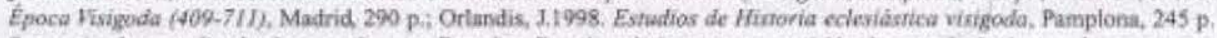

Son varios los estudios hechos por Jacques Fontaine. Pero lo más importante, revisiôn de su tesis de doctorado, en nuestra opinión es Fontaine, 1.

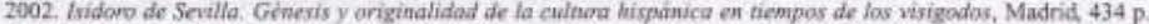

- Destacamos dos transcripciones hechas por la autora. Codoter Merino, C. 1964 . El De etris illustribus 'de fsidoro de Sevilia. Estudio y edición critica, Salamanca, 167 p. Codoñer Merno, C. 1992 isidorus Hispalensis De Differentiis 1, Paris, 537 p.

De los estudios hochos nor Garcia Moreno consideramos como los màs interesantes Garcia Moteno, L. A. 1974. Pmsopmerafia del Reino Virsigo. do de Joledo, Salananca, 247 p; Garcia Moreno, L.A. y Sayas Abengochea, J.l. 1982. Ramanizmo y Germanismo. El surgir de los puebios hispuinicos, Barcelora, 552 p; Garcia Moneno, L. A. 1989. Hisforia de Expaña Visigoda, Madrid, 390 p.

1. Princigalmente Diaz Martinez, PC. 1987 . Former econdimicas y sacialer en el manacuto visigeda, Salananca. $190 \mathrm{p}$.

* El concepto de Antiguedad Tandia aparece desarrollado en estudios como los de Marrou, H.I. 1979. Decadéncia romana ue dintiguidade Tantia?,

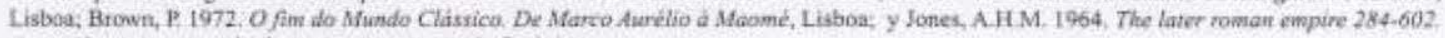
A social, economic and adminisenafive sarvey, Oxford, 2 v

- La ampliación de las bases cropológicas de la Antigiedad Tartia apatece claramente propuesta en trabajos como los de Novo Guisall, $1 . \mathrm{M} .1992$. Las pueblas vasco-cantaboricos y galaricas en la Antigüedad Tardia (siglos III. LX). Alcalà de Henares; y Bois, G. "Sur la 'mutation' de 1'an mil", in: De la Antigizindad al Mfediesa. p. 343-53.

"Respecto a ese tema, ver Garcia Moreno, L.A. "El estado protofeudal visigodo: precedente y modelo para la Europa carolingia", in: L'Europe He.

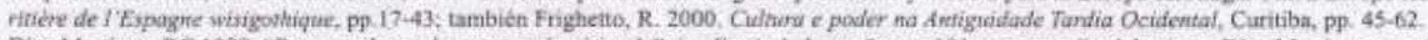

41. Diaz Martinez, PC: 1988, "Rey y poder en la manarquia visigodz", in: Iberia 1, Logroño, pp, 181, otro estudia del mismo Diaz Martinez que si. gue esta misma linea de interpretación es "Visigothic political institutions", in: Soudies in Hirtorical Archaeoethnology 8 - The visigoths from the migration period to the seventh century (Otg. P. Heather), San Marino, 1999, p. $321-48$
}

Revista de Historia, ano 16, vol. 16(2), 2006, pp. 11-19 
en las fuentes con titulos muy sugestivos como seniores, nobiles, potentes, inlustres ${ }^{13}$ y que eran comunes tanto a los nobles de origen germánico como a los nobles vinculados a las antiguas familias senatoriales romanas', fue a lo largo de la Antigüedad Tardia muy dura ya que el soberano tenia su base de apoyo exactamente entre elementos de la alta nobleza que le ofrecian sustentación politica, fideles regis a los cuales el monarca ofrecia beneficios patrimoniales en cambio de su auxilium politico y militar. Por otro lado el rey tenia fuerte oposición de los elementos nobiliarios alejados de su entorno más inmediato. pertenecientes a otros clanes, que tenian interés im extremis en alcanzar el poder regio ${ }^{13}$. Así, notamos que la situación del monarca era bastante delicada: tenia que ganar la confianza y ofrecer beneficios a sus fideles para que éstos le apoyasen contra sus rivales politicos ${ }^{16}$. De tal forma que el soberano estaba delante de un auténtico "maniqueismo" politico: de un lado estaban los clanes que lo apoyaban, mientras en el otro aquellos que se oponian abiertamente a su poder'?

Esta constatación, la existencia de una confrontación entre facciones nobiliarias, nos lleva a una hipótesis de que no habia una fuerte contestación de la nobleza hacia la realeza como institución. Todavia se puede notar una oposición de algunos grupos nobiliarios al noble que ocupaba la condición regia, asi como a todos aquellos que le apoyaban". Así, podemos decir que habia, de facto, un principio de separación entre la res propria y la publica utilitas en los reinos romano-germánicos, particularmente en la cuestión del reconocimiento de la institución regia ${ }^{16}$. Por otro lado hay que recordar que las fuentes tardo-antiguas presentan la nobleza, laica o eclesiástica, como aquella institución que detenia de hecho un fuerte poder de base local y regional siendo, de este modo, la verdadera responsable por toda la presión en contra del proceso de centralización interna llevado a cabo por el poder regio ${ }^{\circ}$. Una constatación que nos lleva a pensar que parte del cuerpo nobiliario tardo-antiguo occidental tenia en la res propria, entendida desde la perspectiva de búsqueda y ampliación de sus poderes políticos y militares en el nivel local y regional, el objetivo de sus acciones prácticas que se oponian directamente a la teórica idea de publica utilitas defendida por el poder regio centralizador y unificador".

Claro está que toda la movilización hecha por el soberano visaba todo lo contrario. Pero su condición de primus inter pares, no la deseada de prinus super pares, dejaba al soberano una posición poco confortable de-

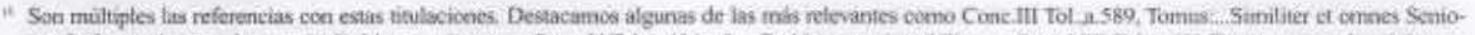

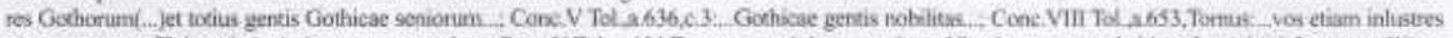

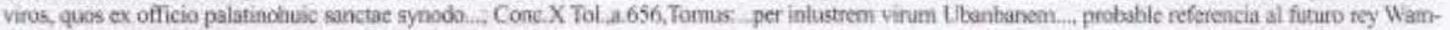

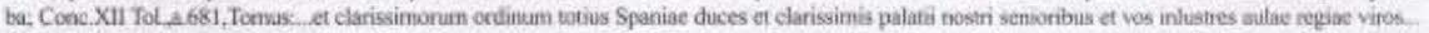

4 Cuestión analizada por Diaz Martinez. PC. "Rey y poder. ", pp. 181-2, "- Los godos estarian al fiente de los poestos de control polinico, pero los roeranos

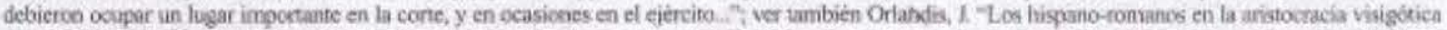

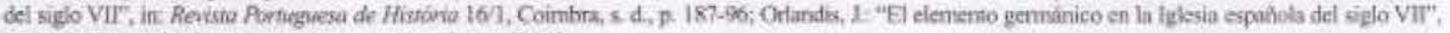
in: La lgiesia en la Esyaria visiguitica y modiesul, pp. 97.149

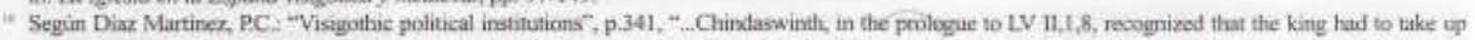
arns more otten against his cows subjects than against forvign exemies. Alibough if should be made clear bere that dhas law is within the connext of ithe repressicn of the nobles, and is a law against treason, against any conspirator or rebel.."

in De acuerdo con Diaz Martines, PC: "Visegothic polstical instinutions", p.347.8, " political instnuments of the monarchy, oc regarding its relarions of power with the clergy and the aristocracy. mechanisens for limiting or coentrolling this powert.... This aristucracy farmed part of them by noyal designation and their iateress were essentially ecoromic and not political." "reforzasdo la idea de que el beneficio otargado a los fideles tenia la connotación de garantia econob.

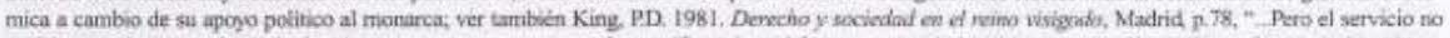
se dabo gratuitamente. La lealtad tenia que lener su pecompensa: la manificencia real fie ura necesidai politica, ya coue solo mediante favores y donaciones a los que estaban a su servicio, podia ef rey esperar de ellos fidelidad.".

"Para venficar esta oposición entre clares nobiliaries ver Sanz Serrano, R. "La exconbunión como sanción politica en el reino visigodo de Tolede", int. Amb-

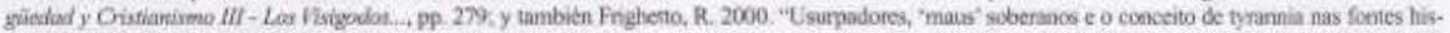

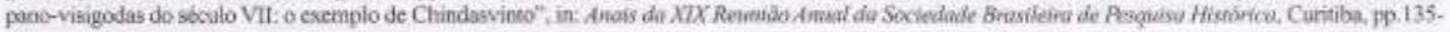
40.

* Las acciones de revancha conma les apoyantes del soberano eran comunes segàn Cone V Tol.,a.636.e.6i" simili providema pro fidelibus regum nosara de. tur gententix C1 quiscuis supprestis principum extitent iuste in rehus profligatis aut lanvitate principis adquisitis nullam deheat hahere iacturam..." Cone. VI

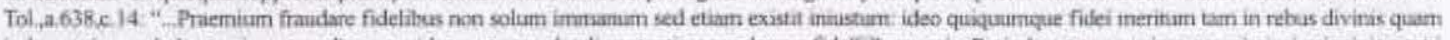

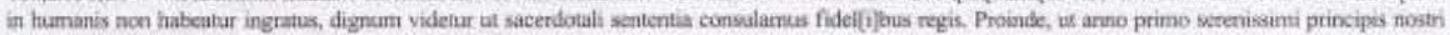

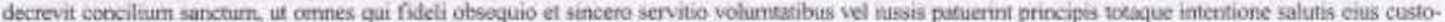
diam vigilantasn habuerin, a regni screcesoribus nec a dignitare nec a rebus pristinis causa repeilantur iniusts, sed et nunc ita pro uninscuisque utilitate principis moderensar discreticeie, sicut eos prospexerit necessarios esse patriae.,"

- Segùn Diaz Martinez, PC. "Visigothic political instinutions", p. 342.3, ". On the ane hand something tike the transpersonal nature of tive State was achieved. the separasion between the achial figure of the King and the idea of royality, a separation between the res proprin and the publicas, utilitas.".

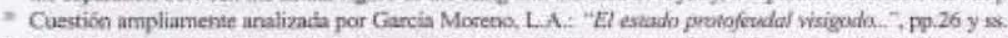

3. La ídea de na propria se mantavo en particular con relación a la cuastión de la patrimonialización de los bienes regios, acción llevada a cabo por la nobie23 tanto laica como eclestastica. Con respecto a esta euestión ver Frigheno, R. 2000. "O curso da vida na Gallaccia hispano-visigoda em finais do secilo VII. o exermplo de Valierio do Bierzo", in: Actas de las Primeras Jornadas de Historia de Fipaha, Buenos Aires, 9.47. 
lante de las facciones nobiliarias ${ }^{2 n}$, ya que en términos generales era considerado un noble como otro cualquiera. Por eso era fundamental la creación de mecanismos, tanto prácticos como teónicos, visibles o no, capaces de elevar al soberano por encima de los demás nobles. El primer mecanismo puede ser aquel que ponia al soberano como responsable y dador de la ley ${ }^{2}$. Debemos entender que la ley, en este caso, venia directamente de la propia divinidad, siendo el soberano su representante encargado de ponerla en práctica ${ }^{24}$. De esta forma el soberano aparece casi siempre vinculado a dos virtudes relacionadas con su actividad legisladora: la iustitia y la pietas que revelan su preocupación por el bienestar de los pueblos ${ }^{31}$. Además de esto tenemos otros mecanismos prácticos y visibles que podrian diferenciar al soberano de los demás nobles: la ciudad regia, centro del poder $\mathrm{y}$ de todas las decisiones políticas, que seria vista como simbolo de la propia monarquía ${ }^{2 t}$; la vestimenta regia, totalmente diferenciada por el color purpúreo, la diadema, el cetro y la corona, complementadas por el trono; y el ritual ceremonial, imitado del emperador romano oriental, que le separaba del contacto directo con la gente más simple, creando una imagen más ideal que real del soberano y de la corte". Junto a estos mecanismos visibles tenemos la formulación, de parte de los representantes de la nobleza eclesiástica, de teorías que buscaban reforzar el carácter descendiente del poder divino en la figura del soberano, presentándole como el ungido de Dios y principal responsable por la unidad y conducción del reino ${ }^{28}$. Una clara e indudable heren-

11. El tema fue tratado en Frigherto, R. 2002. "Uma ternativa de tanidade polticico religiosa na Hispania visigoda de funais do século VIt: o reinado de Eigica", in: Actas de las Segundas Jomadas de Histeria de Espania, Buencs Aires. p.5.4.

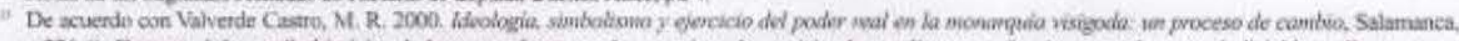

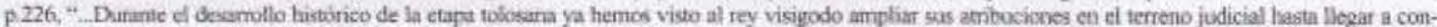

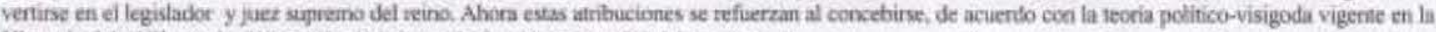
Hisporia del s VII, que la claborscién de la ley es la fineióa primortal del monarcat."

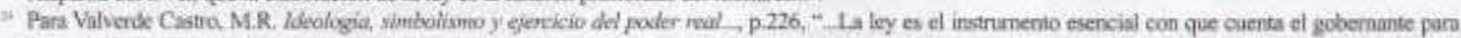
desarrollar su tarea, que bi es otra, scgin los puenulados teocráticos, que dirigir a la sociedad cristiana pana alcarrar el fin decretado por Dios. Consecuente-

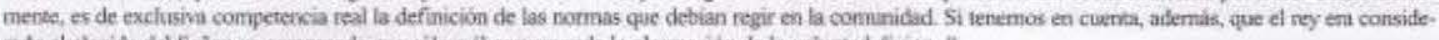
rado el elezibo del Selice; se comprende que sólo a el conresponda la plasmación de la voiuntod diviva...".

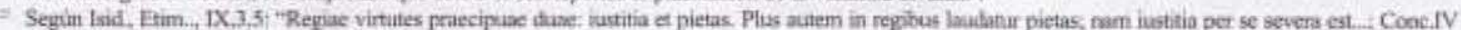

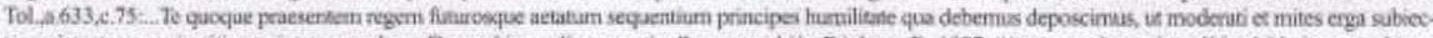

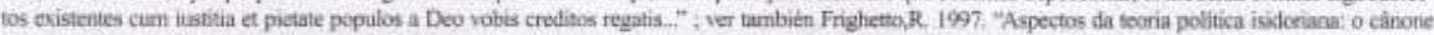
75 do IV Concilio de Toledo e a constituiça monírquica do reino visigodo de Toledo", in: Revista de Ciencias Históricas 12, Porta, pp. 80-1.

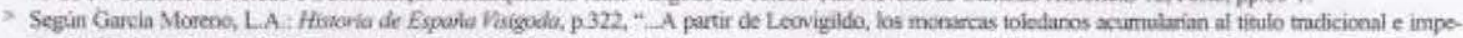
rial de Flavio otros apelativas y tratanientos protocolanios peopias de la sealeza imperial bezartina del seglo V(..). A semiejanza de Constantinopha, Toledo seria pleraroenie confirmada como sede del rimo. La celebración del sinodo arriano del 580 en toledo miciara una langa seria de reaniones cunciliares de ca.

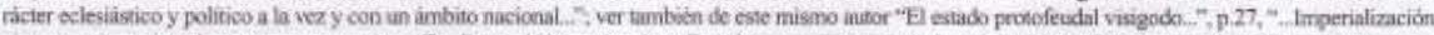

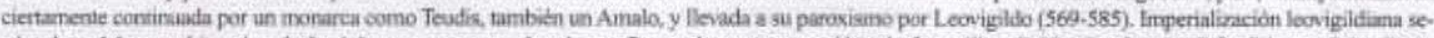

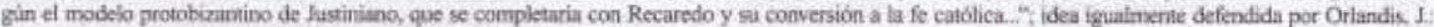

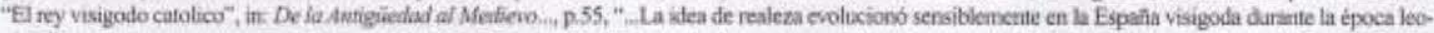

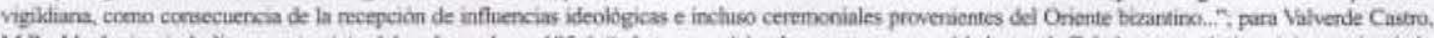

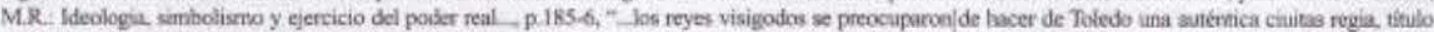

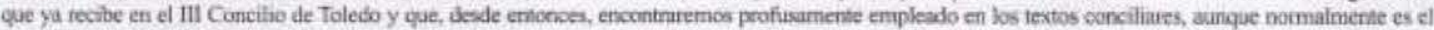
wocablo urba, mis cnnoblecedar, el que se usilias pana hacer referencia a la ciudad de Toloda. Esta denominación, urts negia, era precisamerife la que se dabo a

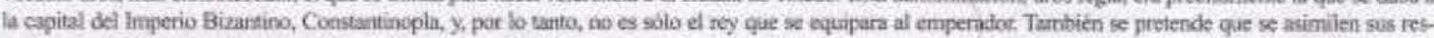

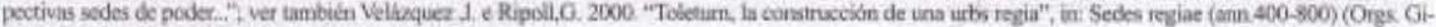
sella Ripoll e Joseph M. Gurt. Butcelona, p.521-77.

*. La influensia del cremonial bizantino en la monarquia hispano-visigods, en particular desde Leovigildo, er presentads por isid., Hist, Goth, 51: primusque

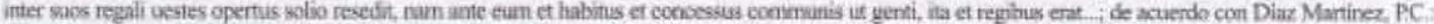

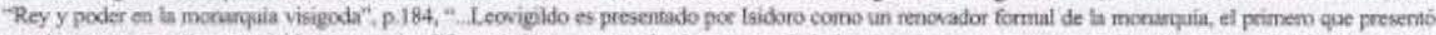

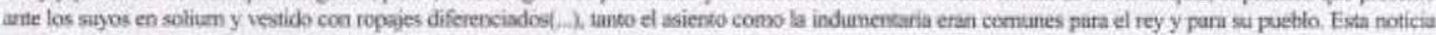

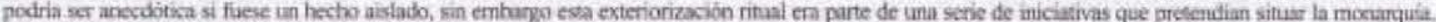
definitianente, en el vénice de la pinianide del onganigrama social y politico de la Hispeaia visigoda; vestido y posición sambolizaban el fagar destacado por encima del puctio y de la aristocracia. "; ver tambièn Valverite Castro, M R. Ideologia, simbolismo y cjercicio del poder real, p.194, "- Mäs elaro se nos ha

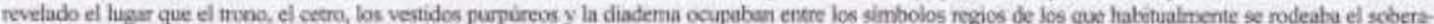
no vaigodo. Todos estas elemenos fonraban parte del orrato de los emperadores romano-bizantinos y, poe lo tamio, pertenecian al mundo cultural menana

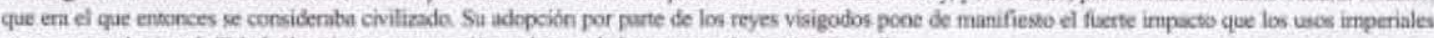
causaron en el reino de Toledo, lo mismo cae ocurrib en el resto de las monseyulas germánicas .u.".

* Varnos estudios tratan de la cuestićn, como Reydellet, M. "La consepticut du souverain cher tsidore de Seville", in: fsidonana, pp.457-66;, Godoy, C. e Vilicla.

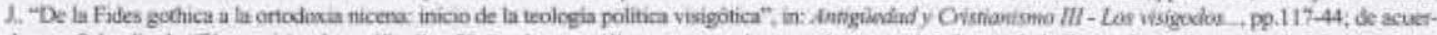

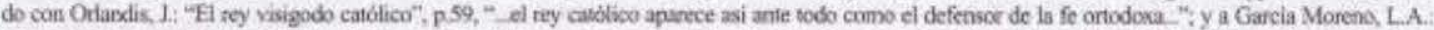

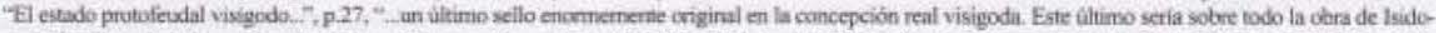

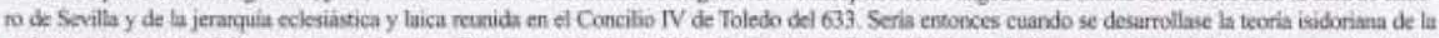

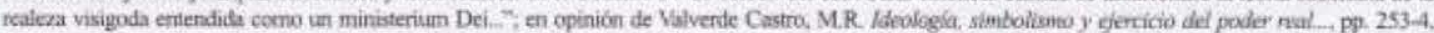
- Podemos concluir, por tanto, que el arigen divino del poder, asi somo la misión salvifica que ha de desarrollar el soberano, son las beses ideolagicas que

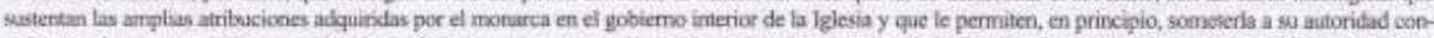

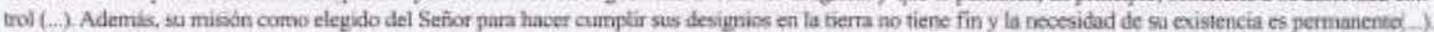

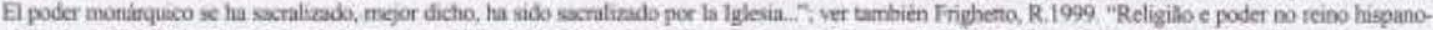

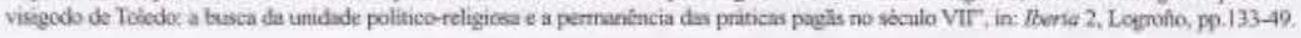

Revista de Hixtoria, año 16 , vol. $16(2), 2006$, pp. 11-19 
cia ideológica rescatada por aquellos pensadores occidentales de la legitimidad teórica del poder regio presente en el pensamiento político bajo imperial, justiniano y oriental".

Ahora bien, la búsqueda por la afirmación teórica del poder regio, en términos políticos y religiosos, es muy visible en el caso hispano-visigodo en el momento de la conversión de la herejia arriana al cristianismo niceno, por ocasión del III Concilio de Toledo del año $589^{30}$. Desde entonces hasta el XVII Concilio de Toledo del 694 , último Concilio hispano-visigodo cuyas actas están presentes únicamente en la recensión Vulgata, la más tardia de la recensiones de la Colección Canónica Hispana", diversos cánones conciliares han presentado construcciones teóricas que tenian la intención de reconocer el poder regio como principal autoridad politica, y también religiosa, del reino hispano visigodo ${ }^{2 z}$. Una señal más de las dificultades del soberano en tener su autoridad reconocida, especialmente por sus rivales nobiliarios laicos. Por eso notamos que los concilios de la Iglesia hispano-visigoda servian, ante todo, como asamblea politica donde el soberano intentaba, a través del reconocimiento de los participantes conciliares, establecer las bases de su poder $^{n}$. Por cierto que esto es otro sintoma de que la contestación a la persona del rey, que acababa por afectar la institución regia, generaba una gran inestabilidad politica interna ya que se contestaba la capacidad del soberano de ejercer su papel de unificador y defensor del reino.

Por otro lado debemos apuntar que en los concilios hispano-visigodos reunidos entre 589 y 694 la defensa teórica del poder del soberano por parte de la nobleza eclesiástica estaba directamente relacionada a la posición politica y militar del rey gobernante, asi como también tenian importancia las relaciones políticas entre los obispos y el rey. O sea, según la fuerza laica de los apoyos regios y su relación amistosa, benevolente y hasta de sumisión respecto a la Iglesia podrian valer al soberano un aporte y apoyo más significativo de la nobleza eclesiástica, constructora de los argumentos teóricos y legitimadores del poder regio". En efecto, cuando analizamos monarcas enérgicos y con fuertes apoyos nobiliarios, casos de Chindasvinto, Wamba o Egica, notamos una cierta "independencia" respecto a las presiones conciliares y, por ende, de la nobleza eclesiástica. Sin embargo esta posición regia podria llegar a la confrontación con aquellos sectores que, a nivel ideológico, sostenian la supremacia del soberano ante toda la nobleza del reino hispano-visigodo. Como culminación de esta actitud de confrontación política del rey encontramos algunas interesantes reacciones llevadas a cabo por la nobleza eclesiástica: desde la damnatio memoriae de Chindasvinto presentada por Eugenio II de Toledo en el epitafio al difunto monarca", hasta las conjuras palaciegas contra Wamba y Egica, organizadas por Juliản de Toledo y Sisberto de Toledo, que llevaron a la deposición del prime-

1* Respecto a la pervivencia de la tradición romano-oriental y bizantina junto al obispado tardo antiguo occidental, Gonzalez Fernandez, R.199e "La obra legislativa de Justiniano y la Cristianización del cosmos", in: Aetighiedad y Cristianismo VII - Cristianismo y acuituración ew riempos del Imperio Romano, Marcia, pp. 495-518.

" Son muchos los estudios que tratan del tema de la conversion de los visigodos en el ill Concilio de Tolodo. De los cuales, como ilustración, citamos Orlandis, L. 1962. "La lglesia vistgoda y los ptoblemss de la sucestín al trono en el siglo Vir", in: Esradios Visigóticos III, Madrid-Ro-

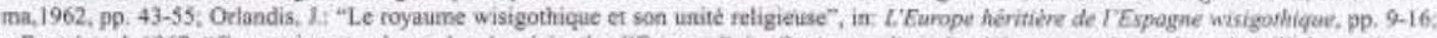

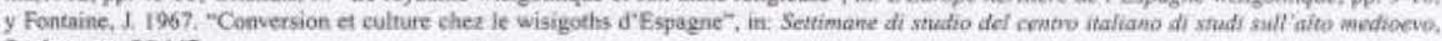
Spoleto, pp, 85-147

" Cf. Orlandis, J. y Ramos Lissón, D. Hisforia de los Concilios..., PP. 496-7, y en la pligina 506 afirma: ".., Las actas de Toledo XVII son las ültimas que nos han llegado de la epoca visigoda. Ello no significa, sin embargo, que fuera este et últime conciliv celebrado can anterioridad a la in. vasión islámica. Tenemos constancia de la reuniobn, cuando menos, de otros dos sinodos toledanos, cuyas actas no se consetvan. .7.

- Conc III Tol., a.589, Edictum regis in confirmatione concilii. Gloriosissimus domnus noster Recaredus rex: Universorum sub regni nostri potesiate consistentium amatores nos suos divina faciens veritas nostris principaliter sensibus inspirwit, ut eausa instaurandse fidei ac disciplinae eccle. sisatieae episcopos omnes Spaniae nostro praesentandos cuimini iuberemus,.; Cone. IV Tol.,a.633, e.75: "De commonitione plebis ne in principes delinquantur"; Cove.Emert., a.666,e.3: "Quid sit observandum tempore quo rex exercitu progreditur pro regis gentis aut patriso statu atque salete". Conc.X1 Jol, a.675,c.15: " principi nostri Ubambani regi gratiarum actiones persolvimis, cuius ordinatione collecti, cuius etiam studio adgregati sumus, quia ecelesiasticae disciplinae his nostris seculis novus reparatot wocurrens..."

Segün Isid., Sent.,III.51,3. "..Sub religionis disciplina saecult potestates stubiectae sunt.,", donde presenta la idea de superioridad de las decisiones religiosas; de acuerdo con Diaz, Martinez, P.C. "Rey y poder..," p.186, "- Los concilios visigodos son en si mismos una institución politica la suprema asamblea legislativa encargada de regular la marcha del estado y el más alto tribunal del reino..."; menos contundente es King, PD Derecho y sociedad. D. 35, ". la serie de concilios generales(-) lo eran sólo en un sentido muy linitado. Su función principal era en realidad apoyar y proteger los intereses, actuaciontes y leyes del rey, regular ciertas cuestiones de significado constitucional y, más frecuentemente, estabiecer las normas de gobierno eclesiástico -; $y$ también Frighetto, R. "Aspectos da teoria politica isidoriana. ", pp.76-7

1. Cuestión analizada por Frighetta, R. 2004. "Algumas consideraçôes sohre o poder na Antiguidade Classica e na Antiguidade Tardia", in: Srilos 14. Buenos Aires, 2004 (en prensa)

" Ce. Frighetto, R.: "Os usurpadores, "maus' soberanos...", p. 136. 
ro y a una durísima reacción del segundo ${ }^{t 0}$. En situación opuesta encontramos los soberanos considerados "débiles", casos de Chintila y Ervigio". Se puede notar en ambos reinados problemas relacionados con el ascenso del monarca al trono y un apoyo limitado por parte de la nobleza laica, que terminarán por llevarlos a buscar apoyo junto a la órbita nobiliaria eclesiástica. Los concilios V, VI, XII y XIII de Toledo, realizados durante aquellos reinados, presentan sintomas de la aproximación del rey hacia la nobleza eclesiástica, especialmente cuando estudiamos temas de interés directo del soberano, como la defensa de la familia regia, la defensa de sus fideles y de todos los beneficios a ellos concedidos y la confirmación de la ascensión al trono. Mas este apoyo tenia un "precio", visible en una serie de contrapartidas beneficiosas a la Iglesia y, consecuentemente, a la nobleza eclesiástica. Las más significativas fueron el reconocimiento políico de las asambleas conciliares, asi como la retirada de los encargos juridicos que pesaban sobre los clérigos acusados de infidelidad, medidas llevadas a cabo en el periodo de Ervigio".

De acuerdo con estas cuestiones podemos decir que el trayecto hecho por la institución monárquica hispano-visigoda a lo largo del siglo VII daba lugar al enflaquecimiento de la figura centralizadora y unificadora del rey, reforzando y consolidando los poderes locales, regionales y tendientes hacia la fragmentación. La ausencia de un princípio válido y único de sucesión regia ${ }^{20}$, ya que gran parte de la nobleza laica defendia la práctica electiva - basada en una tradición tanto germánica ${ }^{40}$ como romana $^{4}$ - en oposición a una gran parcela de la nobleza eclesiástica defensora del principio de la sucesión regia -establecido en la familia del rey a través de la práctica del consortio regnum de tradición romana y orientale- acababa por enflaquecer la posición del soberano. Una salida posible para el soberano de este embrollo politico, visando sobre todo el refuerzo de su condición como primus super pares, podria ser la creación de una teoria basada en la sacralización de la figura regia que culminaba con el signo de la unctio, con el consecuente reconocimiento del poder del soberano segun la perspectiva de que el rey era el escogido de Dios"s. Parece indudable que con esta práctica, descrita por primera vez en occidente en el reinado de Wamba", la imagen del soberano, en tẻrminos teóricos, ganaba robustez frente al cuerpo nobiliario. Pero debemos verificar que las ventajas teóricas no podrian eliminar las desventajas intrínsecas de la unctio, como por ejemplo el hecho de que cabía al obispo de Toledo, metropolitano de la ciudad regia, el papel de legitimador y ejecutor de la voluntad

* Respecto a Wamba, Garcia López, Y.1996, Errudias criticas de la Lex Wisigothonom", Aleali de Henares, p. 215, "-, sabemos que Wumbs tambièn interfirió de forma importante en la regulación de la lalesia y tal vez ello le costó el trono ." sobre la conjura contra Wamba, Frighetto, R. 2002. "Legitimidade e usurpaçăo na Hispania visigoda de finais do século VII: o caso do reinado de Wamba", in: Scripva Antiqua in honorem Angel Montenegro Duque et José Maria Bláxquez Martinez, Valladotid, pp. g41-9; Frighetto, R. 2004. "Uma confrontaçzo régio nobiliárquica na Antiguidade Tardia hispanica: o roi $c$ a nobreba cclesiástica no teinado de Wamba $(672.680)^{7}$, in: Semanes de Esnedios Remanos $X X$, Viñ del Mar (en prensd); con relación a Egica. Frigbetro, R. "Unma tentativa de unidade politico religiosa.,", p.51-69.

7 Para analizar el reinado de Chistils ver Orlandis, I y famos-Lissén, D. Historia de los Concilios..., pp. 302 y ss., con relación a Ervigio ver el re-

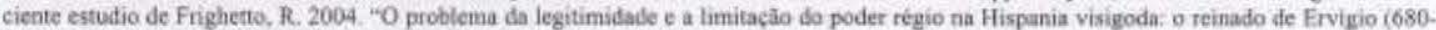
$687)^{\prime \prime}$, in-Geridon 22, Madrid, (en prensa)

" Especiaimente en Conc.XII Tol, a.681, Praef, ", si haec-synodalium decreta gestorum sicut pio devotioais nostrae studio acta sum, ita inconvalsibilis nostrae legis valido oràculo confirmentar.." Conc. XIII Tol, a.683, "Lex in confirmatione concilit edital .. . Eximia syaodalis auctoritas et veneranda est panter et inemenda.."

" Para esta cuestión ver Diaz Martinez, PC. "Rey y poder.", pp. 188-90; y Frighetto, R. "Aspectos da teoria politica isidoriana...", pp.76-9.

* Con relación a la práctica electiva de los germanos, ver Garcia Moreno, L. A. 1986 . "La imvasión del 409 en Espaf́a: nuevas perspectivas desde el punto de vista germano", in: Cincos extudios sohre el mindo antiguo, León, pp.69.72

* Basada sobre todo en la aclanatio imperia, que en opinaón de Rodriguez Gervis, M.): Propaganda polinica y opinibur pubbilica en los Paneginicos latinos del bajo imperio, Salamanca, 1991, p. 36, - . La proclarmación del emperador por el ejército viene condicioneda por la aclamatio por la cua se consigue el poder imperial pleno y la musma legitimidad en la función de imperator que si fuera nombrado sugusto por el Senado. thi para Hidaigo de la Vega, M.J. 1995. El infelectual, la medieza y el poder polinico en el imperio Romano, Salamanca, p. I08. "...el poder del emperador, del basileus romano, se legitimaba por medio de convertit al emperador en un soberano, además de legitimo, 'carismático'.."

4N De acuerdo con Valverde Castro, M.R. Ideologia, simbolismo y ejencieio del poder rool, pp. 181-2, " La asociación no daba derecho a la asunción del titulo real ni implicaba la asignación de unos dominios especificos en los que ejercer funciones soberanas, Se trató de una medida teradiente a asegurar la sransmisión bereditaria del poder y, por tante, a sustraer del arbitrio y los manejos de la nobleza la decisión de quién habria de ser el sucesor real, to que podria hacer estallar disputas soceserias a la muerte del monarea reinante..."

* Respecto a esta cuestión ver nota 28, De manera más detallada Valverde Castro, M. R. Reologia, simbolismo y ejereicio def poder reat., p. 204. "- el exponente más representativo del carícter sactal que adquicec la monarquia visigoda en la Hispania del s. VII lo constituye el rito de la un. cióa real. A través de esta ceremonia mayestätica se sanciona, de forma práctica, la teoria politico-religiosa sobre la monarquia, poniendo solemsnemente de manifiesto que el rey es el elegido de Dios.."

* Como indica Carcia Mcreno, L. A. "El estado protofeuchal visigodo. ", p. 28, "...la ceremenia de ta unción real, testimoniada con seguridad a partir de Wamba (672), con bastante anterioridad a la inaugurada por los priacipes de la casa de Heristal.,."; ver también Frighetto, $R$ "Legitimidin. de e usurpaçio na Hispania visigota...", pp. 845.

Revista de Historia, año 16, vol. 16(2), 2006, pp. 11-19 
celeste $^{45}$. O sea, el rey estaba una vez más en una condición de debilidad, ahora con respecto a la nobleza eclesiástica hispano-visigoda.

De este modo podemos sacar algunas consideraciones parciales con respecto a nuestras investigaciones. Primeramente que la realidad política existente entre los siglos IV y VIII en los reinos romano- germánicos establecidos en la Pars Occidentalis del mundo imperial romano, donde la unidad monárquica centralizadora daba lugar a la fragmentación y fortalecimiento de los poderes locales y regionales, es caracteristica de la Antigüedad Tardia, periodo de transición entre la Antigüedad Clásica y la Edad Media. Pero no podemos olvidar que esta Antigüedad Tardia, en el mediterráneo occidental, también se caracteriza como período en el cual se mantuvieran ideas y formas culturales que denotan una continuidad del pensamiento politico y cultural del mundo clásico. Por lo tanto la noción de unidad y centralización política, defendida por sectores de la nobilitas eclesiảstica, es una herencia del pensamiento imperial romano que fue reestructurada en la Antigüedad Tardia en el ámbito del cambio de la Romanitas a la Christianitas".

La consecuencia más directa de esta realidad política fue la confrontación entre el rey, defensor de las perspectivas centralizadoras y unitarias del poder politico, y la nobleza, que buscaba sobre todo la manutención de sus poderes locales y regionales. Además debemos tener en cuenta que otras cuestiones también colaboraban decisivamente para esta confrontación: como la forma de ascensión al trono por parte del rey; y las disputas entre clanes nobiliarios que apoyaban al rey o le hacian oposición abierta. De hecho, en términos prácticos, la nobleza tenia medios de persuasión bastante eficaces, pues era ella que poseía la fuerza políticomilitar de los séquitos privados y armados que apoyaba y mantenia al rey en su cargo. Por eso apuntamos que la nobleza tenia un pensamiento político más volcado hacia la res propria, ya que apoyar a un soberano vinculado a su clan podria traer mayores ventajas patrimoniales $y$, por ende, más poderes politicos en sus regiones de origen. Así podemos decir que el soberano, en nuestro caso el hispano-visigodo, no tenia condiciones de gobernar o ejercer su poder de manera independiente, sin el apoyo directo de una parte de la nobleza.

Esta incomoda posición en la cual se encontraba el soberano limitaba, y mucho, cualquier acción que llevase hacia la centralización $\mathrm{y}$, como consecuencia, a la unidad politica del reino. Por cierto que las teorias de sacralización de la figura del rey, construcciones basadas sobre todo en las tradiciones bíblica, patristica, bajo imperial romana y romano-oriental, buscaron fortalecer la posición del soberano ante todo el cuerpo nobiliario. Teorias que eran complementadas por signos externos que realzaban aún más la imagen de superioridad del soberano sobre los demás miembros de la nobleza y que tenian en la unctio su máxima expresión.

Asi podemos decir que contra el poder político militar efectivo de la nobleza el rey intentó buscar en las construcciones teóricas e ideológicas las bases de la consolidación de su poder como primus super pares, con especial acento en torno a las uirtutes propias del buen gobernante, la iustitia y la pietas. Pero esta táctica regia tenia un fallo elemental pues estaba basada sobre columnas muy frágiles ya que los elementos teoricos son más ideales que reales. Sin lugar a dudas la fuerza de los séquitos militares nobiliarios hablaria más alto que cualquier teoria a la hora de la elevación o deposición del rey. Y los constructores de aquellas teorias, como Isidoro de Sevilla o Julián de Toledo, cambiaban incluso de opinión con relación al soberano que, como Suintila o Wamba, fueron alabados y valorizados teóricamente y a posteriori depuestos y acusados de no respetaren las uirtutes con las cuales eran adornados hasta poco antes de su deposición. Muy apropiada para este caso es la máxima de Lucano de que virtud y poder supremo no pueden convivir juntos, o sea, teoria y práctica politica son dos realidades complejas y, en muchos casos, distantes una de la otra. Un descompás visible que puso al rey y la nobleza en campos opuestos y que llevó al enflaquecimiento politico e institucional del reino hispano-visigodo de Toledo a lo largo del siglo VII.

\footnotetext{
"En opinión de Diaz Martinez, PC. "Rey y podet..", p.190, ".El tey se convertia asi en un elegido de Dies, pero evidentemente el sacramento debla ser administrado por los obispos, lo que ayuda a entender el papel que éstos iban a tener en la elericalización del oficio real, y ritualimente se formalizaba la supremacia de los sacerdotes respecto a los principes. En este sentido podemos imterpretar que la unción es muestra no de la fuerza de la monarquia, sino de su debilidad..".

" Sobre esta cuestión Frighetto, R. "Algumas consideraçбes sabre o podet.." (en prensa).
} 


\section{BIBLIOGRAFIA}

Azcárraga Servet, J. (Org.) 1993. De la Antigüedad al medievo (siglos IV-VIII) - III Congreso de Estudios Medievales, Avila.

Brown, P. 1972. O fim do Mundo Clássica. De Marco Aurélio d̀ Maomé, Lisboa.

Codoñer Merino, C. 1964. El 'De viris illustribus' de Isidoro de Sevilla. Estudio y edición critica, Salamanca.

Codoñer Merino, C. 1992. Isidorus Hispalensis. De Differentiis I, Paris,

Diaz y Diaz, M.C. 1958. Anedocta Wisigothica I - Estudios y ediciones de textos literarios menores de época visigoda, Salamanca.

Diaz y Diaz, M.C. 1982. "Introducción general", in: Oroz Reta, J. y Marcos Casquero, M.A. San Isidoro de Sevilla - Etimologias I, Madrid.

Diaz Martinez, P.C. 1987. Formas económicas y sociales en el monacato visigodo, Salamanca.

Diaz Martinez, P.C.1988. "Rey y poder en la monarquia visigoda", in: Iberia 1, Logroño.

Diaz Martinez, P.C. 1999. "Visigothic political institutions", in: Studies in Historical Archaeoethnology 4

- The visigoths from the mignation period to the seventh century (Org. P. Heather), San Marino, p. 321-48.

Fontaine, J.1967. "Conversion et culture chez le wisigoths d'Espagne", in: Settimane di studio del centro italiano di studi sull'alto medioevo, Spoleto, pp. 86-147.

Fontaine, J. 2002. Isidoro de Sevilla. Génesis y originalidad de la cultura hispánica en tiempos de los visigodos, Madrid.

Fontaine, J. y Pellistrandi, Ch. (Orgs.) 1992, L'Europe Héritière de l'Espagne Wisigothique, Madrid.

Frighetto, R. 1997. "Aspectos da teoria politica isidoriana: o cânone 75 do IV Concilio de Toledo e a constituição monárquica do reino visigodo de Toledo", in: Revista de Ciencias Históricas 12, Porto, pp, 80-1.

Frighetto, R. 1999. "Religião e poder no reino hispano-visigodo de Toledo: a busca da unidade políticoreligiosa e a permanência das práticas pagãs no século VI", in: Iberia 2, Logroño, pp. 133-49.

Frighetto, R. 2000 a. Cultura e poder na Antiguidade Tardia Ocidental, Curitiba.

Frighetto, R. 2000 b. "Usurpadores, 'maus' soberanos e o conceito de tyrannia nas fontes hispano-visigodas do século VII: o exemplo de Chindasvinto", in: Anais da XIX Reunião Anual da Sociedade Brasileira de Pesquisa Histórica, Curitiba, pp.135-40.

Frighetto, R. 2000 c. "O curso da vida na Gallaecia hispano-visigoda em finais do século VII: o exemplo de Valério do Bierzo", in: Actas de las Primeras Jornadas de Historia de España, Buenos Aires, p.47.

Frighetto, R. 2002 a. "Uma tentativa de unidade político religiosa na Hispania visigoda de finais do século VII: o reinado de Egica", in: Actas de las Segundas Jornadas de Historia de España, Buenos Aires, p. 54.

Frighetto, R. 2002 b. "Legitimidade e usurpação na Hispania visigoda de finais do século VII: o caso do reinado de Wamba", in: Scripta Antiqua in honorem Angel Montenegro Duque et José Maria Blázquez Martinez, Valladolid, pp.841-9.

Frighetto, R, 2004 a. "Algumas consideraçôes sobre o poder na Antiguidade Clássica e na Antiguidade Tardia", in: Stilos 14, Buenos Aires, 2004 (en prensa).

Frighetto, R. 2004 b. "Uma confrontação régio nobiliárquica na Antiguidade Tardia hispanica: o rei e a nobreza eclesiástica no reinado de Wamba (672-680)", in: Semanas de Estudios Romanos XX, Viña del Mar (en prensa); con relación a Egica.

Frighetto, R, 2004 c. "O problema da legitimidade e a limitação do poder régio na Hispania visigoda: o reinado de Ervigio (680-687)", in:Gerión 22, Madrid (en prensa).

Garcia López, Y. 1996. Estudios criticos de la 'Lex Wisigothorum', Alcalà de Henares.

Garcia Moreno, L.A. 1974. Prosopografia del Reino Visigodo de Toledo, Salamanca.

García Moreno, L.A.1986, "La invasión del 409 en España; nuevas perspectivas desde el punto de vista germano", in: Cinco estudios sobre el mundo antiguo, León, pp.69-72. 
Garcia Moreno, L.A. 1989. Historia de España Visigoda, Madrid.

Garcia Moreno, L.A. 1992. "El estado protofeudal visigodo: precedente y modelo para la Europa carolingia", in: L'Europe Héritière de l'Espagne wistgothique, pp. 17-43.

Garcia Moreno, L.A. y Sayas Abengochea, J.J. 1982. Romanismo y Germanismo. El surgir de los pueblos hispánicos, Barcelona.

González Blanco, A. (Org.). 1986. Antigüedad y Cristianismo III - Los Visigodos. Historia y Civilización, Murcia.

González Fernández, R. 1990. "La obra legislativa de Justiniano y la Cristianización del cosmos", in: Antigüedad y Cristianismo VII - Cristianismo y aculturación en tiempos del Imperio Romano, Murcia, pp. $495-518$.

Hidalgo de la Vega, M.J.1995. El intelectual, la realeza y el poder politico en el Imperio Romano, Salamanca.

Jones, A.H.M. 1964. The later roman empire 284-602. A social, economic and administrative survey, Oxford. 2 y.

King, P.D. 1981. Derecho y sociedad en el reino visigodo, Madrid.

Marrou, H.I. 1979. Decadência romana ou Antiguidade Tardia?, Lisboa.

Novo Guisán, J.M.1992. Los pueblos vasco-cantábricos y galaicos en la Antigüedad Tardia (siglos III$[X)$, Alcalá de Henares.

Orlandis, J.1962. "La Iglesia visigoda y los problemas de la sucesión al trono en el siglo VII", in: Estudios Visigóticos III, Madrid-Roma, pp. 43-55.

Orlandis, J. 1976a. La lglesia en la España visigótica y medieval, Pamplona.

Orlandis, J. 1976b. "El elemento germánico en la Iglesia española del siglo VII", in: La Iglesia en la España visigótica y medieval, pp. 97-149.

Orlandis, J. 1987. Historia de España - Epoca Visigoda (409-711), Madrid.

Orlandis, J.1998. Estudios de Historia eclesiástica visigoda, Pamplona.

Orlandis, J. "Los hispano-romanos en la aristocracia visigótica del siglo VII", in: Revista Portuguesa de História 16/1, Coimbra,s.d., p. 187-96.

Orlandis, J. 1992. "Le royaume wisigothique et son unité religieuse", in: LEurope héritière de l'Espagne wisigothique, pp.9-16.

Orlandis, J. y Ramos Lissón, D. 1986. Historia de los Concilios de la España romana y visigoda, Pamplona.

Rodriguez Gervás, M.J. 1991. Propaganda politica y opinión pública en los Panegiricos latinos del bajo imperio, Salamanca.

Sánchez Albornoz, Cl. 1974. En torno a los origenes del Feudalismo - Fideles y gardingos en la monarquía visigoda. Raices del vasallaje y del beneficio hispanos. Libro I, Tomo I, Buenos Aires.

Sanz Serrano, R. "La excomunión como sanción politica en el reino visigodo de Toledo", in: Antigüedad y Cristianismo III - Los Visigodos. Historia y civilización, pp. 279.

Valverde Castro, M. R. 2000. Ideologia, simbolismo y ejercicio del poder real en la monarquia visigoda: un proceso de cambio, Salamanca.

Velázquez, I. y Ripoll, G. 2000. "Toletum, la construcción de una urbs regia", in: Sedes regiae (ann.400800) (Orgs. Gisella Ripoll e Joseph M. Gurt), Barcelona, pp. 521-77.

Villapalos Salas, G. (Org.) 1998. Los Visigodos y su mundo - Arqueologia, Paleontologia y Etnografia, Madrid. 